\title{
PANDEMIC ALERT LEVEl 6: SCIENTIFIC CRITERIA FOR AN INFLUENZA PANDEMIC FULFILLED*
}

\author{
Eurosurveillance editorial team (eurosurveillance@ecdc.europa.eu) ${ }^{1}$ \\ 1. European Centre for Disease Prevention and Control, Stockholm, Sweden
}

The World Health Organization (WHO) today announced the decision to raise the level of influenza pandemic alert from phase 5 to phase 6 [1]. This makes the current influenza $A(H 1 N 1) v$ outbreak officially a pandemic.

In its press conference at 18:00 CETS, the WHO emphasised that the severity of the pandemic is, at least currently, moderate. Countries are advised to concentrate on mitigation measures as appropriate for their specific situation. They are not advised to close borders or restrict international traffic and trade as there is no evidence that these measures stop the spread of the disease and are unnecessarily disruptive for international traffic and trade.

At the same time, vaccine manufacturers are working on the production of influenza vaccine specific for the pandemic strain.

\section{Criteria}

The pandemic alert phases 5 and 6 reflect the global spread of the outbreak. They do not necessarily reflect a graduation of the severity of the disease in the individual.

While phase 5 is defined as sustained community level outbreaks in at least two countries within a single WHO region, phase 6 , the pandemic, is declared when sustained, community-wide human-to human transmission occurs in at least one additional WHO region [2].

The move to pandemic phase 6 is a response to the fact that according to WHO the spread of influenza $A(H 1 N 1) v$ in several countries can no longer be traced to clearly-defined chains of human-to-human transmission and that the scientific criteria for an influenza pandemic have been met.*

As of 11 June, the number of laboratory-confirmed cases of influenza $A(H 1 N 1) v$ worldwide amounts to 28,774, with 144 deaths [3].

\section{Implications}

In response to the WHO declaring a pandemic, all countries affected by influenza $A(H 1 N 1) v$ should consider activating national pandemic plans and to implement the measures detailed in them. They include monitoring and reporting of cases, monitoring of resources and compliance, ensuring the availability of vaccine and antiviral drugs, potential limitations on travel and mass gatherings, insuring business continuity, and informing and educating the public.
This has economical implications and puts a strain on staff involved in the pandemic in many areas. However, many of the above measures have already been in place since the declaration of pandemic phase 5. For the individual country, the real change is the moment when it becomes affected, i.e. when it starts seeing significant transmission in the community, whereas the formal move to phase 6 may not imply large changes to the way it is dealing with the situation. According to the ECDC, the declaration of pandemic phase 6, which can be expected to last for several months, does not change the present ECDC risk assessment [4].

Phase 6 is the highest level of pandemic alert. It can be difficult to understand for non-experts why this is triggered in response to a disease that, at least at this stage, is mild in the majority of people, with a low mortality rate published for North America [5]. This can lead to confusion and uncertainty in the population, especially with the tendency of parts of the media to over-emphasise the sensational aspect of such news. This is why the WHO today emphasised once more that the term 'pandemic' describes the geographic spread of the disease rather than its severity and is a means of coordinating world-wide preventive measures.

*Erratum: The following changes were made on 12 June 2009. The title was changed to "Pandemic alert level 6: Scientific criteria for an influenza pandemic fulfilled" and the third paragraph under the heading "Criteria" to "The move to pandemic phase 6 is a response to the fact that according to WHO the spread of influenza A(H1N1)v in several countries can no longer be traced to clearly-defined chains of human-to-human transmission and that the scientific criteria for an influenza pandemic have been met."

\section{References}

1. World Health Organization. Current WHO phase of pandemic alert. [Accessed 11 June 2009]. Available from: http://www.who.int/csr/disease/avian_influenza/ phase/en/

2. World Health Organization. Pandemic Influenza Preparedness and Response. Geneva: World Health Organisation; 2009.

3. World Health Organization. Influenza A(H1N1) - update 47. June 11, 2009. Available from: http://www.who.int/csr/don/2009_06_11/en/index.html

4. European Centre for Disease Prevention and Control. ECDC situation report. Influenza A(H1N1)v infection. Update 11 June 2009, 17:00 hours CEST. Available from: http://www.ecdc.europa.eu/en/files/pdf/Health_topics/Situation_ Report_090611_1700hrs.pdf

5. Fraser C, Donnelly CA, Cauchemez S, Hanage WP, Van Kerkhove MD, Hollingsworth TD, et al. Pandemic Potential of a Strain of Influenza A (H1N1): Early Findings. Science. 2009 May 14. [Epub ahead of print].

This article was published on 11 June 2009

Citation style for this article: Eurosurveillance editorial team. Pandemic alert level 6: Scientific criteria for an influenza pandemic fulfilled. Euro Surveill. 2009;14(23):pii=19237. Available online: http://www.eurosurveillance.org/ViewArticle. aspx?ArticleId $=1923$ 